\title{
Mechanochemical mechanism of rapid dechlorination of hexachlorobenzene
}

\author{
Shanshan Deng ${ }^{\mathrm{a}, \mathrm{b}}$, Shaoguo Kang ${ }^{\mathrm{c}}$, Nannan Feng ${ }^{\mathrm{a}, \mathrm{b}}$, Jianxin Zhu ${ }^{\mathrm{a}, \mathrm{b}, *}$, Bo Yu ${ }^{\mathrm{d}}$, \\ Xiaofeng Xie ${ }^{\mathrm{d}}$, Jing Chen ${ }^{\mathrm{d}}$ \\ a Department of Solid Waste Treatment and Recycling, Research Center for Eco-Environmental Sciences, Chinese Academy of Sciences,18 Shuangqing Road, \\ Beijing 100085, China \\ ${ }^{\mathrm{b}}$ University of Chinese Academy of Sciences, Beijing 100049, China

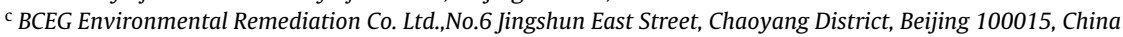 \\ ${ }^{\mathrm{d}}$ Institute of Nuclear and New Energy Technology, Tsinghua University,Haidian District, Beijing 100084, China
}

\section{A R T I C L E I N F O}

\section{Article history:}

Received 9 December 2016

Received in revised form 20 February 2017

Accepted 10 March 2017

Available online 12 March 2017

\section{Keywords:}

Mechanochemical treatment

Free radical reaction

Dechlorination mechanism

Density functional theory (DFT)

Hexachlorobenzene (HCB)

\begin{abstract}
A B S T R A C T
Recent researches indicate that mechanochemical treatment (MCT) is a promising method to degrade the environmental hazards, especially in the area of persistent organic pollutants (POPs) disposal. However, the mechanochemical dechlorination mechanism of POPs still needs to be further verified. In this mechanochemical process, hexachlorobenzene (HCB) was chosen as a model pollutant with aluminum and alumina $\left(\mathrm{Al}+\mathrm{Al}_{2} \mathrm{O}_{3}\right)$ powders as the co-milling regents. Both of the intermediate analysis and quantum chemical calculations were adopted to elucidate the free radical dechlorination mechanism of HCB. The solid residues were characterized by electron spin-resonance (ESR) spectroscopy, Fourier transform infrared (FTIR) spectra and X-ray photoelectron (XPS) spectra, which proposed that the radicals formed in the mechanochemical process were chlorinated phenoxyl radicals $\left(\mathrm{CB}-\mathrm{O}^{\bullet}\right)$. Four quantum chemical descriptors were selected in predicting the intermediates and reaction pathway: (i) atomic charge, (ii) electrostatic potential (ESP), (iii) frontier molecular orbitals (FMO) theory and (iv) dual descriptor. Then, a stepwise dechlorination mechanism based on $\mathrm{CB}-\mathrm{O}^{\bullet}$ was proposed. It was found that the intermediates and radical-related reactions in the mechanochemical dechlorination of $\mathrm{HCB}$ are quite different from that happen in a typical photocatalytic dechlorination process. Impacts of different radical reactions on the dechlorination of HCB were also compared at last.
\end{abstract}

(C) 2017 Elsevier B.V. All rights reserved.

\section{Introduction}

Mechanochemistry is a branch of chemistry [1,2], named to illustrate the chemical and physicochemical transformations of substances triggered by mechanical force, such as shearing, friction, shock and squeeze [3-6]. Mechanochemical method has been widely used in extractive metallurgy [7-9], material synthesis [10,11], powder surface modification [12] and hazards attenuation [13-15]. Compared with conventional procedures, mechanochemical technology has several main advantages: no-combustion, solvent-free, low energy consumption, less $\mathrm{CO}_{2}$ and hazardous byproducts emissions, possible implementation process etc.

\footnotetext{
* Corresponding author at: Department of Solid Waste Treatment and Recycling, Research Center for Eco-Environmental Sciences, Chinese Academy of Sciences, 18 Shuangqing Road, Beijing 100085, China.

E-mail address: zhujx@rcees.ac.cn (J.Zhu).
}

$[4,6,16,17]$. Therefore, mechanochemical treatment(MCT) has been listed as one of the most promising no-combustion and eco-friendly technologies for the disposal of the persistent organic pollutants (POPs), such as 1,3,5-trichlorobenzene, 3-chlorobiphenyl, 4-chloroaniline, $\gamma$-hexachlorocyclohexane, dioxins, mirex, pentachlorophenol and polychlorinated biphenyls [18-24].

It has been proven by plenties of studies that free radical is one of the key elements in the MCT process [25-28], which can induce and accelerate the dechlorination and degradation process. Some investigations demonstrated the formation of triboplasma [25,29]; it has been deemed to be a highly energetic state containing highly ionized gas [30]. The degradation of tetrabromobisphenol A (TBBPA) and $\mathrm{HCB}$ through a milling method gave credit to the generation and transportation of radicals [25,27,31]. The relationship between the degradation rates of POPs and the yield of paramagnetic products was also verified in the MCT of mono-chlorobiphenyl [32]. The oxygen-centered aromatic radical $\left(\mathrm{Ar}-\mathrm{O}^{\bullet}\right)$ was proposed in the MCT of 3-chlorobiphenyl (BP-Cl) and pentachlorophenol [23,26]. How- 

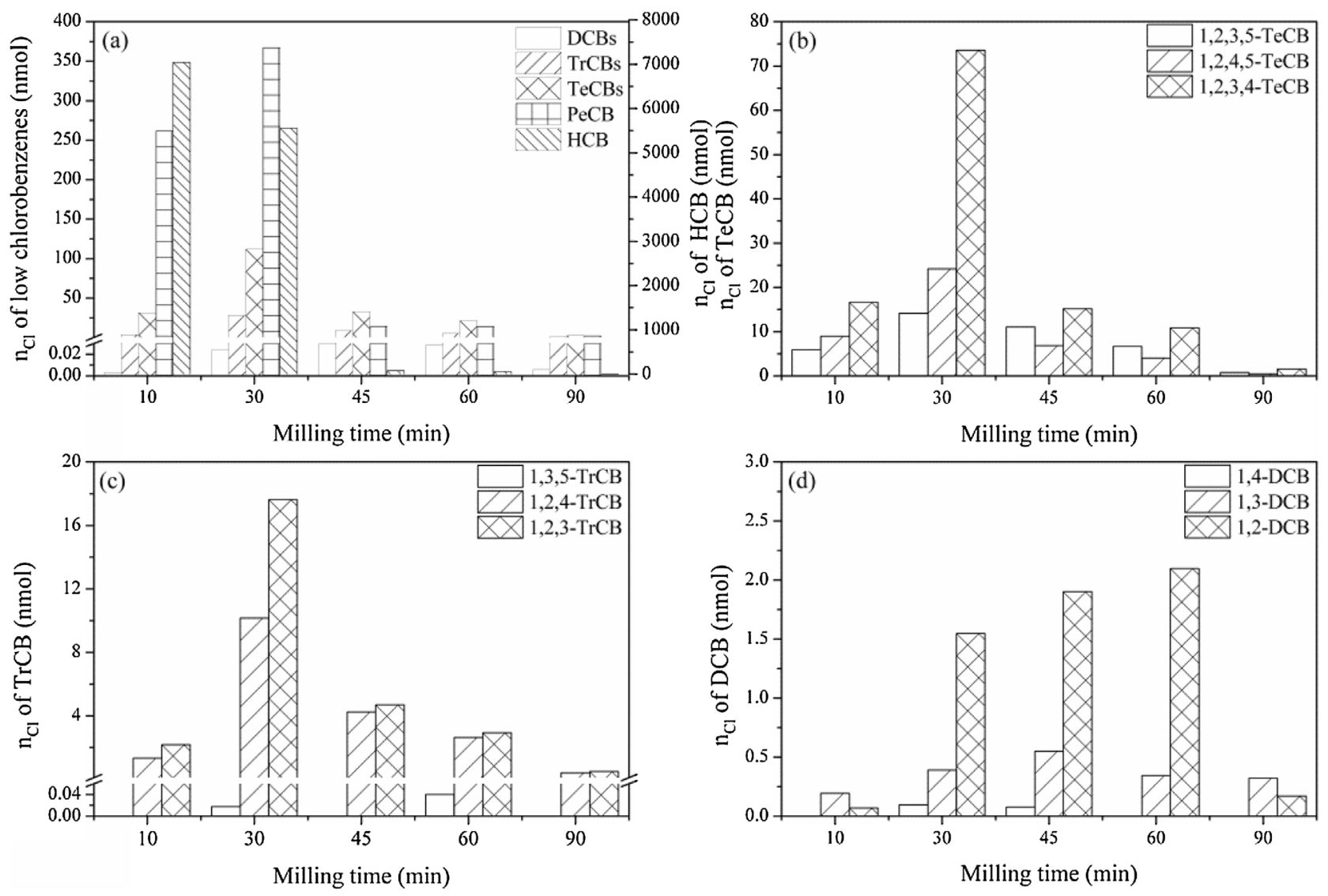

Fig. 1. Degradation of HCB and formation of low-chlorinated isomers in the MCT process: (a) CBz congeners, (b) TeCBs isomers, (c) TrCBs isomers and (d) DCBs isomers.

ever, the details of this radical-related dechlorination route are hard to obtain from previous studies. Hence, clarification and description of the radical reaction mechanism in the mechanochemical dechlorination process is a steep and urgent challenge for understanding the nature of MCT.

Recently, many researchers used quantum chemical calculation, especially density functional theory (DFT), to investigate the mechanism behind the degradation of organic pollutants [33-35]. Quantum chemical descriptors can be exploited to characterize specific molecular properties and predict active sites of the certain reaction. These descriptors were defined to indicate molecular structure and chemical properties, which have been put into use successfully [36]. This train of thought provides insight into the mechanisms perspicuity that cannot be elucidated solely based on experimental data. Several typical descriptors, such as atomic charge [37], frontier molecular orbital (FMO) theory [38], electrostatic potential (ESP) [39], Fukui function [40] and dual descriptor [41], are entirely based on electronic characteristics of reactants, so most of them are cheap and efficient $[42,43]$. Moreover, composite of several methods can enhance the reliability of theoretical prediction [44]. Several kinds of descriptors were performed synergistically in some DFT studies [45-47].

As for the reason why Metal $/ \mathrm{Al}_{2} \mathrm{O}_{3}$ was selected as the co-milling regent of $\mathrm{MCT}$ of $\mathrm{HCB}$, many previous studies demonstrated its effectiveness in the organic pollutants treatment from their excellent adsorption and chemical composition properties [48-52]. HCB was selected as the model pollutant due to its universality, typical symmetry and polysubstitution. The intermediates during the MCT process were analyzed regularly to provide the basic information for the mechanism study. In addition, four quantum chemical

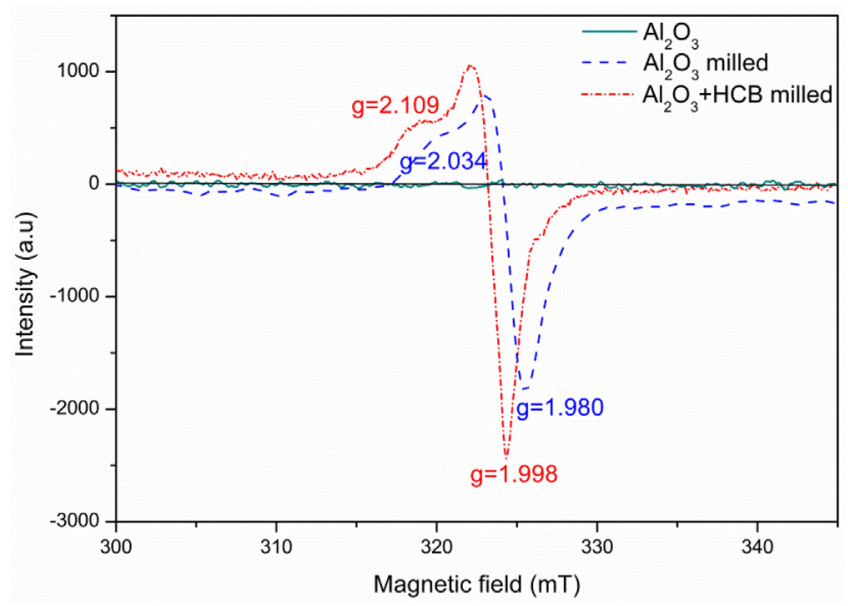

Fig. 2. ESR of initial $\mathrm{Al}_{2} \mathrm{O}_{3}$ sample (cyan line) and samples grinding $90 \mathrm{~min}$ (blue for $\mathrm{Al}_{2} \mathrm{O}_{3}$ and red line for $\mathrm{Al}_{2} \mathrm{O}_{3}+\mathrm{HCB}$ samples). (For interpretation of the references to colour in this figure legend, the reader is referred to the web version of this article.)

descriptors, atomic charge, ESP, FMO theory and dual descriptor, were employed to predict the active sites and validate the radical reactions expected. Finally, a systematic solid state step-wise dechlorination mechanism in the MCT of HCB was proposed based on both experiments and quantum calculations. Impacts of different radical reactions on the dechlorination of $\mathrm{HCB}$ were also compared at last. 


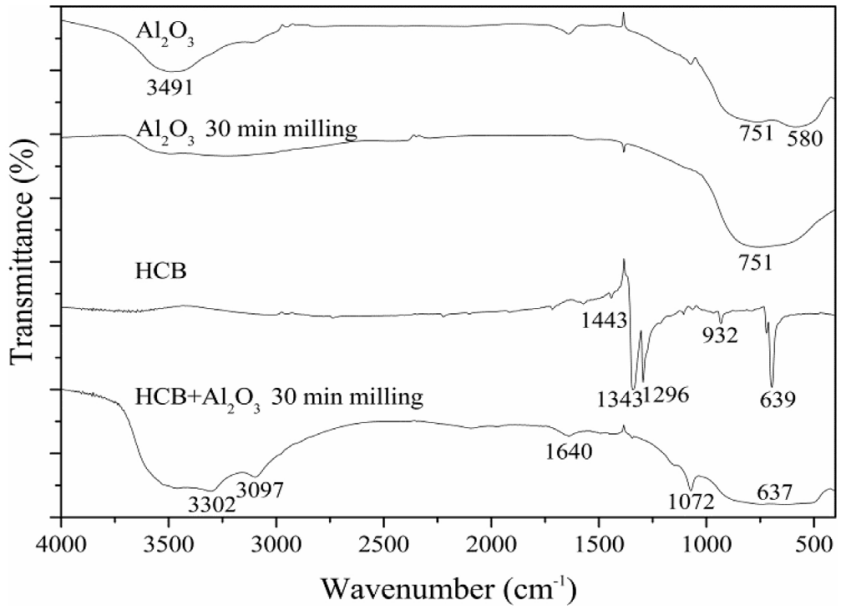

Fig. 3. FTIR spectra of ground samples.

\section{Materials and methods}

\subsection{Materials}

HCB (purity 99\%) was purchased from Beijing HWRK Chem Co., Ltd. CBz standards of chlorobenzene produced by Accu Standard Inc. were used for gas chromatography-mass spectrometry (GC-MS) analysis, including $\mathrm{HCB}$, pentachlorobenzene (PeCB), tetrachlorobenzenes (TeCBs, including 1,2,3,4-TeCB, 1,2,3,5-ТeCB and 1,2,4,5-TeCB), trichlorobenzenes (TrCBs, including 1,2,3-TrCB, $1,2,4-\operatorname{TrCB}$ and 1,3,5-TrCB), dichlorobenzenes (DCBs, including 1,2-DCB, 1,3-DCB and 1,4-DCB) and monochlorobenzene (MCB). Anhydrous sodium sulfate (GR, Sino pharm Chemical Reagent Co., Ltd, China) were heated in a muffle furnace at $400^{\circ} \mathrm{C}$ for $6 \mathrm{~h}$ before using and stored in a dryer prior. The milling additives were aluminum powder ( $\mathrm{Al}, 30 \mu \mathrm{m}$ grade, Sino pharm Chemical Reagent Co., Ltd, China) and aluminum oxide $\left(\mathrm{Al}_{2} \mathrm{O}_{3}, 300 \mu \mathrm{m}\right.$, Sino pharm Chemical Reagent Co., Ltd, China). Normal hexane (Fisher Scientific) and acetone (Fisher Scientific) were at HPLC grade.

\subsection{Ball milling experiments}

All ball milling experiments were carried out in a planetary ball mill (QM-3SP2J), sold by Nanjing University Instrument Corporation, China. $3 \mathrm{~g} \mathrm{Al}, 3 \mathrm{~g} \mathrm{Al}_{2} \mathrm{O}_{3}$ and $0.3 \mathrm{~g} \mathrm{HCB}$ were put into a milling pot. Both of the milling pots $(250 \mathrm{~mL}$ ) and balls (about $180 \mathrm{~g}$, $\Phi 10 \mathrm{~mm}$ ) were made of stainless steel. Milling experiments were operated at a rotation speed of $550 \mathrm{rpm}$ with a charge ratio of 30:1 and additive to HCB mass ratio of 20:1.

\subsection{Analytical procedures}

The residual HCB and dechlorinated intermediates were detected by chromatography-mass spectrometry (GC-MS, Agilent 7890), and the detailed procedure for sample preparation and detection can be found in the Supplementary Material. Radicals were observed using the electron spin-resonance (ESR) spectroscopy. Samples for ESR analysis were specifically prepared using a zirconia pot $\left(\mathrm{ZrO}_{2}\right)$ and balls, eliminating the interference of Fe. After milling for certain times, samples were immediately transferred into the $5 \mathrm{~nm}$ diameter quartz tubes to be measured at the $\mathrm{X}$ band $(9.6 \mathrm{GHz}$, Bruker ESR-380E). Fourier transformed infrared (FTIR) spectra were detected to determine the functional groups of samples. The apparatus model is Nicolet 6700 , made by ThermoFisher using $\mathrm{KBr}$ disk method with the wave number from 400 to $4000 \mathrm{~cm}^{-1}$. The X-ray photoelectron (XPS) spectra of the $01 \mathrm{~s}$ were

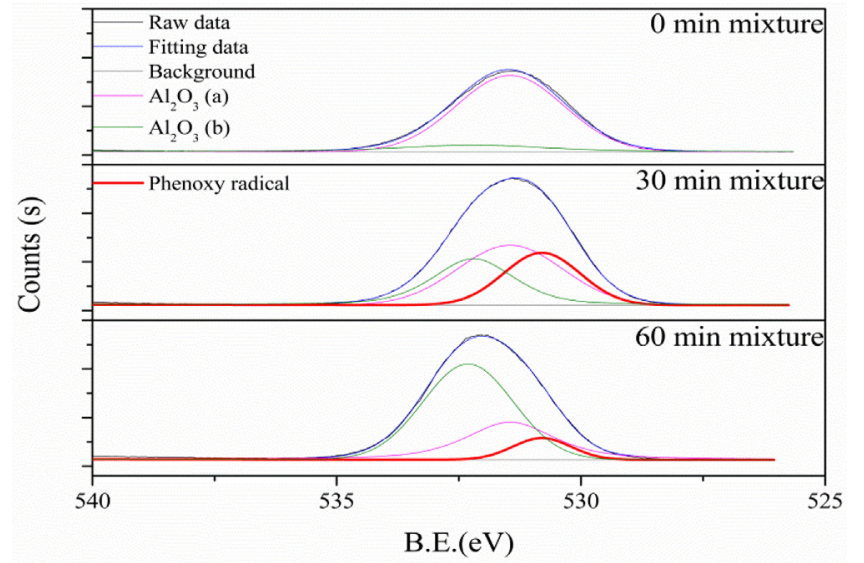

Fig. 4. XPS spectra (O 1s) of ground samples. (For interpretation of the references to colour in this figure legend, the reader is referred to the web version of this article.)

recorded with a step size of $0.05 \mathrm{eV}$ using an ESCALAB 250Xi instrument (Thermal fisher) set at a constant analyzer pass energy of $30.0 \mathrm{eV}$.

\subsection{Degradation pathway analysis by quantum chemical calculation}

All calculations of this article were carried on Gaussian 09W [53], and the molecular constructing and visualizing were performed with Gaussian View 5.0.9. Equilibrium geometry optimizations of all structures, followed by frequency calculations were operated by the DFT Becke3LYP (B3LYP) method. B3LYP, the three-parameter hybrid density model, which is the most popular DFT method including a mixture of Hatree-Fock exchange and DFT exchange correlation, has been employed by many quantum calculation processes [54]. Split valance basis sets 6-31G (d) and 6-311G (d) were utilized to the optimizations and single point energy calculations, respectively $[55,56]$. Gibbs free energies were calculated based on the single point energies and the thermal corrections. Zero-point corrections, thermal corrections and correction factors were all taken into account for the Gibbs free energy change $(\Delta G)$ calculations and the Gibbs free energy of free electron was $-3.6160 \mathrm{~kJ} / \mathrm{mol}$ [57]. Calculations for quantum chemical descriptors to predict the reactive site of the radical reactions, including atomic charge, ESP, FMO theory and dual descriptor, were carried out with Multiwfn, the multifunctional wave function analysis [58], and details for these methods can be seen in the Supplementary Material.

\section{Results and discussion}

\subsection{Experimental dechlorination pathways of $H C B$ in the $M C T$ process}

The time courses for the dechlorination of HCB and the formation of low-chlorinated isomers in the MCT process are shown in Fig. 1(a-d). After 60 min of milling with $\mathrm{Al}$ and $\mathrm{Al}_{2} \mathrm{O}_{3}, 99.3 \%$ of $\mathrm{HCB}$ was degraded in the MCT process with $\mathrm{Al}$ and $\mathrm{Al}_{2} \mathrm{O}_{3}$ as co-milling reagents (see Fig. $S 1$ in Supplementary Material). The role of oxides has been probed in some reports [26]. Gerd Kaupp [59] proposed that mechanical collision and friction can induce the crack of strong covalent bonds and trigger chemical reactions on the surface of oxides. $\mathrm{Al}_{2} \mathrm{O}_{3}$ in the milling system can also prevent the formation of agglomerates, increase the effective interparticulate contact area and promote mechanochemical reactions [22,26].

The congeners of low-chlorinated isomers in the MCT process detected by GC-MS, including PeCB, TeCBs, TrCBs, DCBs and MCB. 
Table 1

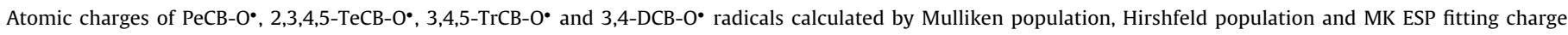
analysis.

\begin{tabular}{|c|c|c|c|c|}
\hline Structure & \multirow{2}{*}{ Atom } & Mulliken & Hirshfeld & MK ESP \\
\hline & & 0.4415 & 0.0608 & 0.3961 \\
\hline & 2 & -0.1361 & 0.0017 & -0.1588 \\
\hline & 3 & -0.0897 & 0.0162 & 0.1110 \\
\hline & 4 & -0.0820 & 0.0029 & -0.0382 \\
\hline & 5 & -0.0897 & 0.0162 & 0.1117 \\
\hline & 6 & -0.1361 & 0.0017 & -0.1605 \\
\hline & & & & \\
\hline & 1 & 0.4451 & 0.1055 & 0.5660 \\
\hline & 2 & -0.1641 & -0.0270 & -0.2667 \\
\hline & 3 & -0.0581 & 0.0227 & 0.0454 \\
\hline & 4 & -0.0829 & 0.0354 & -0.0717 \\
\hline & 5 & -0.0730 & 0.0123 & 0.0527 \\
\hline & 6 & -0.1395 & 0.0269 & -0.1127 \\
\hline & 1 & 0.4280 & 0.1090 & 0.5178 \\
\hline & 2 & -0.1614 & -0.0247 & -0.2193 \\
\hline & 3 & -0.0609 & 0.0237 & 0.0236 \\
\hline & 4 & -0.0856 & 0.0358 & 0.1150 \\
\hline & 5 & -0.0609 & 0.0237 & 0.0234 \\
\hline & 6 & -0.1614 & -0.0247 & -0.2198 \\
\hline & 1 & 04196 & 0,0070 & 0.5480 \\
\hline & 2 & -0.1538 & 0.0682 & -0.2660 \\
\hline & 3 & -0.1183 & 0.0560 & -0.0756 \\
\hline & 4 & -0.0770 & 0.0651 & 0.0525 \\
\hline & 5 & -0.0625 & 0.0813 & 0.0871 \\
\hline & 6 & -0.1665 & 0.0678 & -0.2429 \\
\hline
\end{tabular}

The concentration of MCB was too low to be quantified accurately, so it was not presented in the figures. Fig. 1a shows the contents of PeCB, TeCBs, TrCBs and DCBs in residuals that increase in the first $30 \mathrm{~min}$ and then decrease with increment of milling time. It shows that $\mathrm{PeCB}$ is the prominent lower-chlorobenzene intermediates through the whole process. Relative concentration changes of the low-chlorinated isomers indicates the stepwise dechlorination pathway.

Fig. 1(b) shows that $1,2,3,4-\mathrm{TeCB}$ is the prominent tetrachlorobenzene intermediate, whose concentration is much higher than the other two isomers, implying that ortho- $\mathrm{Cl}$ might be the most preferred position to be removed in the $\mathrm{PeCB}$ dechlorination. While, the concentration of 1, 2, 4, 5-TeCB was on the similar level to that of $1,2,3,5-\mathrm{TeCB}$, indicating similar preference for the dechlorination of $\mathrm{PeCB}$ at the sites of meta- $\mathrm{Cl}$ and para- $\mathrm{Cl}$. Fig. 1(c) shows that $1,2,3-\operatorname{TrCB}$ and $1,3,5-\operatorname{TrCB}$ are the prominent and unremarkable trichlorobenzene intermediate isomers in the ball milling, respectively. Fig. 1(d) depicts the distribution of DCBs in the milled samples, where, 1, 2-DCB holds the largest concentration among the three kind of dichlorobenzene intermediates. It can be concluded that the main dechlorination pathway for HCB in the MCT process could be depicted as follows: $\mathrm{HCB} \rightarrow \mathrm{PeCB} \rightarrow 1,2,3,4-$ $\mathrm{TeCB} \rightarrow 1,2,3-\operatorname{TrCB} \rightarrow 1,2-\mathrm{DCB} \rightarrow \mathrm{MCB}$.

\subsection{Radicals observed in mechanochemical degradation of $H C B$}

Large amounts of free radicals were produced during the milling of $\mathrm{Al}_{2} \mathrm{O}_{3}$, so ESR was employed to detect the mechano-radicals. This was also reported by Zhang and Huang et al. in the grinding of $\mathrm{CaO}, \mathrm{SiO}_{2}$ and other oxides $[27,60]$. Fig. 2 shows the ESR spectra of the original $\mathrm{Al}_{2} \mathrm{O}_{3}$ powder (cyan curve), $\mathrm{Al}_{2} \mathrm{O}_{3}$ powder grounded (blue curve) and mixtures of $\mathrm{Al}_{2} \mathrm{O}_{3}+\mathrm{HCB}$ grounded (red curve) for 90 min. Unground $\mathrm{Al}_{2} \mathrm{O}_{3}$ showed no radical signals, while apparent signals can be seen at around $324 \mathrm{mT}$ in ground samples. The blue curve depicts the signal of milled $\mathrm{Al}_{2} \mathrm{O}_{3}$, with a sharp signal at $\mathrm{g}=1.980$ and a broad signal at $\mathrm{g}=2.034$. The first one indicates the trapped electron on $\mathrm{Al}_{2} \mathrm{O}_{3}$ surface, which is smaller than the free electron $g_{e}=2.002$. It was reported that lattice surfaces of $\mathrm{Al}_{2} \mathrm{O}_{3}$, originally terminated with an oxygen layer, would capture hydrogen to neutralize the surface charge, thus the oxygen layer turns into the structure terminated with hydroxyl groups $[61,62]$. The milling process can destruct hydroxyl layer, lead to deprotonation, induce the release of free electrons and create fresh surface with large amounts of active $\mathrm{O}^{2-}$ sites. These electrons and active $\mathrm{O}^{2-}$ sites on oxide surfaces could transfer to organic compounds to produce large amounts of radicals under the pressure, collision, extrusion and friction in the MCT process [26,32].

The ESR spectra of the milled $\mathrm{Al}_{2} \mathrm{O}_{3}+\mathrm{HCB}$ sample (red curve) shows two peaks at $\mathrm{g}=1.998$ and 2.109. Similar with the milled $\mathrm{Al}_{2} \mathrm{O}_{3}$ sample, the first sharp signal indicated trapped electrons on $\mathrm{Al}_{2} \mathrm{O}_{3}$ surface. The last broad signal was slightly deviated and enhanced compared to the milled $\mathrm{Al}_{2} \mathrm{O}_{3}$ sample, implying that addition of organic matters changed the structures and species of radicals. The radicals might be the chlorinated phenoxyl radicals $\left(\mathrm{CB}-\mathrm{O}^{\bullet}\right)$, which was the resultant of reactions between $\mathrm{HCB}$ and trapped electrons or $\mathrm{O}^{2-}$ on the surface of the milled $\mathrm{Al}_{2} \mathrm{O}_{3}$ particles. The oxygen-centered aromatic radicals were also observed and verified in several MCT researches [19,23,26].

FTIR spectra analysis was also conducted to identify transformations of structures under milling. The FTIR spectra of original 


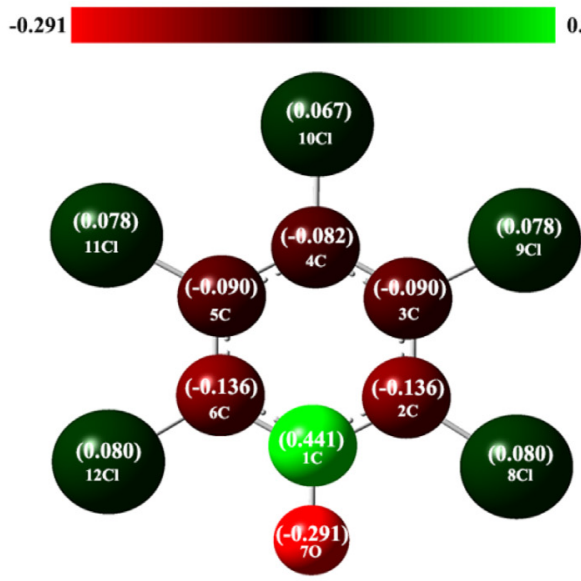

(a) $\mathrm{PeCB}-\mathrm{O}^{*}$

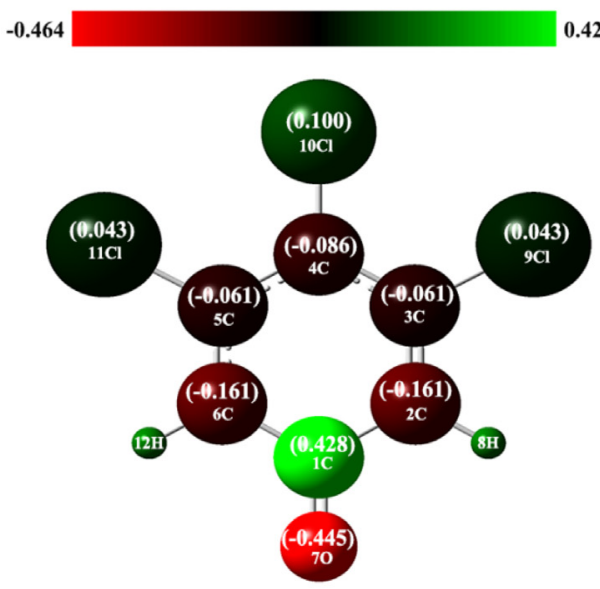

(c) $3,4,5-\operatorname{TrCB}-\mathrm{O}^{*}$
$0.441-0.445$

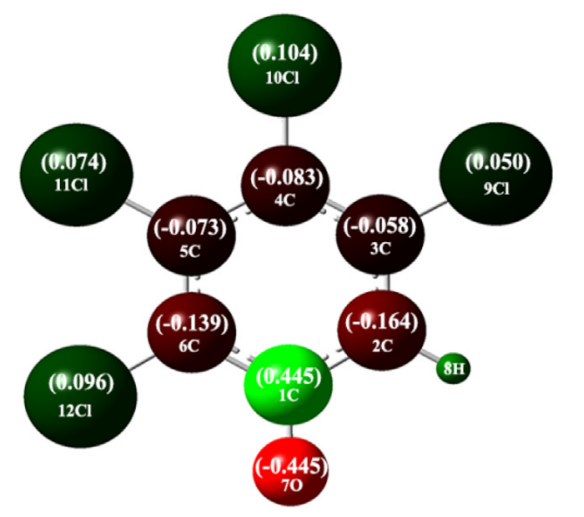

(b) 2,3,4,5-TeCB-O•

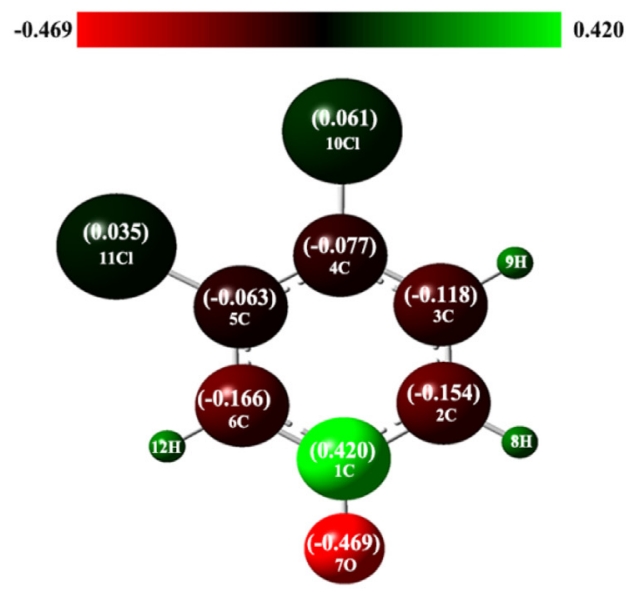

(d) $3,4-\mathrm{DCB}-\mathrm{O}^{\bullet}$

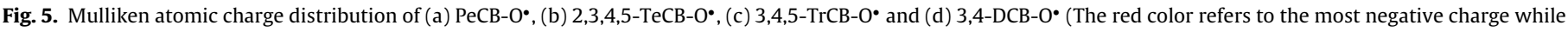
green for positive). (For interpretation of the references to colour in this figure legend, the reader is referred to the web version of this article.)

$\mathrm{Al}_{2} \mathrm{O}_{3}$, milled $\mathrm{Al}_{2} \mathrm{O}_{3}$, original $\mathrm{HCB}$ and milled $\mathrm{HCB}+\mathrm{Al}_{2} \mathrm{O}_{3}$ samples are shown in Fig. 3. The evident differences between the spectra of original and milled $\mathrm{Al}_{2} \mathrm{O}_{3}$ might be due to the water transformations on the surface of $\mathrm{Al}_{2} \mathrm{O}_{3}$. Conforming to the ESR spectra, this result implies that MCT destruct the original water species and hydroxyl groups on the surface of $\mathrm{Al}_{2} \mathrm{O}_{3}$. Peaks at the position of 696 and $932 \mathrm{~cm}^{-1}$ indicate the $\mathrm{C}-\mathrm{Cl}$ stretching vibration of HCB molecules [63]. Peaks at 1296, 1343, and $1443 \mathrm{~cm}^{-1}$ can be conventionally attributed to benzene rings. In the spectrum of milled $\mathrm{HCB}+\mathrm{Al}_{2} \mathrm{O}_{3}$ samples, peaks of the $\mathrm{C}-\mathrm{Cl}$ stretching vibration were overlapped with the vibration of $\mathrm{Al}-\mathrm{O}$ bond. The peaks $(\mathrm{C}-\mathrm{H}$ vibration of aromatic compounds) at the positions around 1072 and $3097 \mathrm{~cm}^{-1}$ were mainly from the dechlorination intermediates of $\mathrm{HCB}$. The new peak exhibited at $1640 \mathrm{~cm}^{-1}$ was resulted from the vibration of $\mathrm{C}-\mathrm{O}$ bonds and could be used as the monitor of $\mathrm{CB}-\mathrm{O}^{\bullet}$. The above findings clearly demonstrated the dechlorination of $\mathrm{HCB}$ and the formation of $\mathrm{CB}-\mathrm{O}^{\bullet}$.

XPS was applied to detect the chemical environment of oxygen (Fig. 4). For the original $\mathrm{Al}_{2} \mathrm{O}_{3}$, two typical peaks were measured at $531.45 \mathrm{eV}$ and $532.20 \mathrm{eV}$, which are attributed to the oxygen with different reactivity in $\mathrm{Al}_{2} \mathrm{O}_{3}$. The former indicates the inert oxygen in the lattice, while the relative active oxygen on the surface for the latter. The milling process would increase the surface area and promote the deprotonation reaction (as mentioned in the ESR and FTIR analysis), so the former peak became weaker and the latter one was stronger along with the milling. In other words, the inert lattice oxygen transforms into the active oxygen on surfaces, which could dramatically increase the reactivity of the MCT. Moreover, a new peak indicating the phenoxyl radical $(530.8 \mathrm{eV})$ appeared after 30 min milling, demonstrating the formation of $\mathrm{CB}-\mathrm{O}^{\bullet}$ in the $\mathrm{MCT}$ process.

\subsection{Dechlorination pathways of $\mathrm{HCB}$ and formation of peCB-O• predicted by quantum chemical calculation}

The abundance of PeCB in the milling process showed in Fig. 1 indicated the speedy dechlorination of $\mathrm{HCB}$, which should be mainly from the reactions of $\mathrm{HCB}$ with the electrons and active $\mathrm{O}^{2-}$ on $\mathrm{Al}_{2} \mathrm{O}_{3}$ surface. This process might be the preferred dechlorination pathway in the mechanochemical system and was modeled by quantum chemical calculation in this study. The values of $\Delta G$ for the major reactions among $\mathrm{HCB}, \mathrm{O}^{2-}$ and electrons were calculated and shown in equations (1-4).

$$
\begin{aligned}
& \mathrm{HCB}+e^{-} \rightarrow \mathrm{HCB}^{-} \Delta \mathrm{G}=463.3410 \mathrm{~kJ} / \mathrm{mol} \\
& \mathrm{HCB}^{-} \rightarrow \mathrm{PeCB}^{\bullet}+\mathrm{Cl}^{-} \Delta \mathrm{G}=-503.5708 \mathrm{~kJ} / \mathrm{mol} \\
& \mathrm{HCB}^{-} \rightarrow \mathrm{PeCB}^{-}+\mathrm{Cl} \bullet \mathrm{G}=-352.8209 \mathrm{~kJ} / \mathrm{mol} \\
& \mathrm{PeCB}^{\bullet}+\mathrm{O}^{2-} \rightarrow \mathrm{PeCB}-\mathrm{O}^{\bullet}+2 e^{-} \Delta \mathrm{G}=-1601.1728 \mathrm{~kJ} / \mathrm{mol}
\end{aligned}
$$

Hexachlorobenzene anion $\left(\mathrm{HCB}^{-1}\right)$ could be produced when the HCB molecule encounters the electron-rich activated surface 


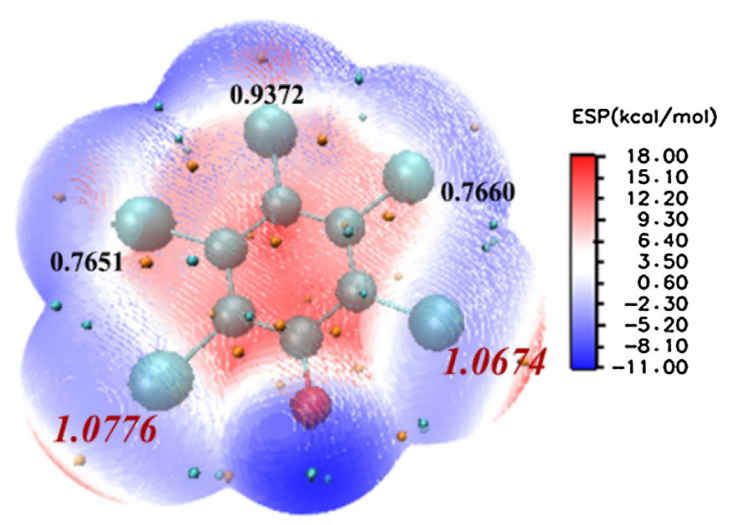

(a) $\mathrm{PeCB}-\mathrm{O}^{\bullet}$

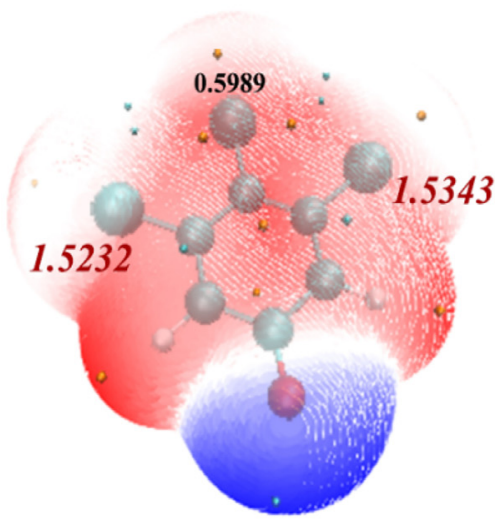

(c) $3,4,5-\operatorname{TrCB}-\mathrm{O}^{\bullet}$

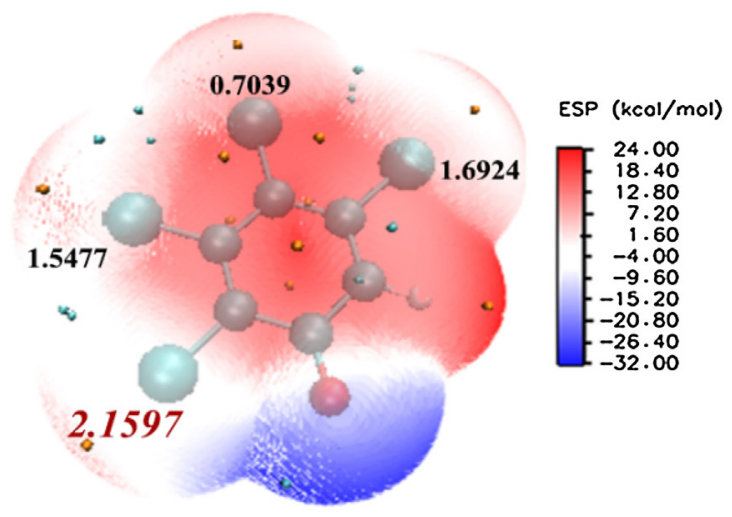

(b) $2,3,4,5-\mathrm{TeCB}-\mathrm{O}^{\bullet}$

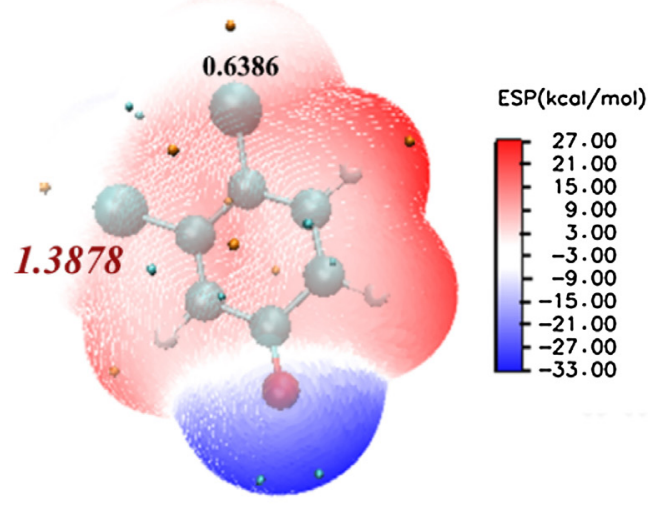

(d) $3,4-\mathrm{DCB}-\mathrm{O}^{\bullet}$

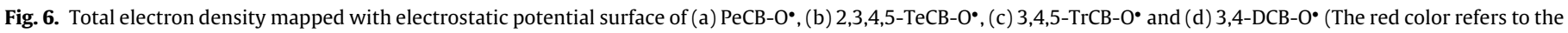

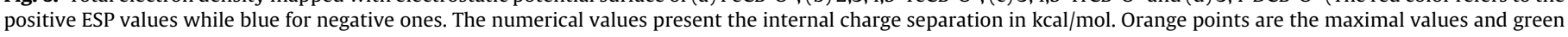

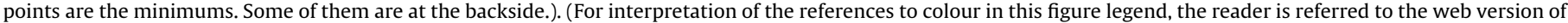
this article.)

induced by grinding, as shown in equation (1) [26,33,64,65]. This reaction is an endothermic process, so certain amounts of energy was needed to promote the reaction. Then, the redundant electron in the HCB molecule causes the relatively strong electronegativity and weakens $\mathrm{C}-\mathrm{Cl}$ bond of $\mathrm{HCB}^{-1}$. The mean $\mathrm{C}-\mathrm{Cl}$ bond length of $\mathrm{HCB}^{-1}$ is about $0.02 \AA$ higher than that of $\mathrm{HCB}$, leading to a tendency to dissociate. The $\mathrm{HCB}^{-1}$ would yield a $\mathrm{PeCB}$ radical $\left(\mathrm{PeCB}^{\bullet}\right)$ and a stable ionic chlorine $\left(\mathrm{Cl}^{-}\right)$, as shown in equation (2), which is an exothermic reaction. Calculation results also validated this rule; energy released for dissociating into $\mathrm{PeCB} \bullet$ and $\mathrm{Cl}^{-}$was much higher than that for $\mathrm{PeCB}^{-}$and $\mathrm{Cl}^{\bullet}$, as shown in equation (3). Finally, equation (4) shows the generation of the pentachlorinated phenoxyl radical $\left(\mathrm{PeCB}-\mathrm{O}^{\bullet}\right.$ ), which occurs between $\mathrm{PeCB}^{\bullet}$ and active oxygen $\left(\mathrm{O}^{2-}\right)$. In these reactions, oxides act as electron and oxygen donors, inducing formation of $\mathrm{HCB}^{-1}$ and $\mathrm{PeCB}-\mathrm{O}^{\bullet}$ [23].

\subsection{Dechlorination routes from $\mathrm{PeCB}$ to $\mathrm{MCB}$ predicted by quantum chemical descriptors}

According to the above analysis, the $\mathrm{CB}-\mathrm{O} \bullet$ based pathways were supposed to be the major routes of dechlorination of HCB. The fate of the radicals after removal of one chlorine might have two possibilities at least: 1 ) reaction with inorganic species (e.g. $\mathrm{O}^{2-}$ or occasionally water) leads to further dehalogenation, and the products are hydrogenated by the solvent; 2 ) reaction with other organic intermediates (e.g. $\mathrm{CB}^{-} \mathrm{O}^{\bullet}$ or $\mathrm{CB}^{\bullet}$ ) after chlorine expulsion. The lat- ter can bring to polymerization and carbonization, which is a very well-known process under milling $[21,25]$. The present study aims to elucidate the mechanochemical mechanism of rapid dechlorination and research on the chief radicals in this system, so the polymerization pathway was not described in detail. Actually, in the milling jar, possible sources of hydrogen are confined to atmospheric humidity and water in the oxides (adsorbed water, crystal water and bound water), besides, the amounts are also limited. To simplify the quantum chemical calculations and catch the nature of dechlorination in the MCT, the hydrogen addition was supposed to currently happen just after the loss of chlorine. Main dechlorination products of all of the oxygen containing low-chlorinated radicals, including $\mathrm{PeCB}-\mathrm{O}^{\bullet}, \mathrm{TeCB}^{-} \mathrm{O}^{\bullet}, \operatorname{TrCB}-\mathrm{O}^{\bullet}$, and $\mathrm{DCB}-\mathrm{O}^{\bullet}$, were predicted by four quantum chemical descriptors. Atomic charge and ESP analysis pay attention to the electrostatic effects at different sites, while FMO and dual descriptor mainly focus on the difference of electron density [44]. The electrostatic effects determine whether the radical can be pulled into the reaction site to attack the $\mathrm{C}-\mathrm{Cl}$ bond, and the difficulty level of the bond breakage depends on the electron density at the site. Therefore, both of electrostatic effects and electron density should be considered to gain a more accurate identification of reaction route.

Atomic charge, one of the most simplest and straightforward chemical descriptors in chemical systems, was employed to predict the active sites and the dechlorination route [66]. In general, substitution was preferred to take place at the position of the car- 


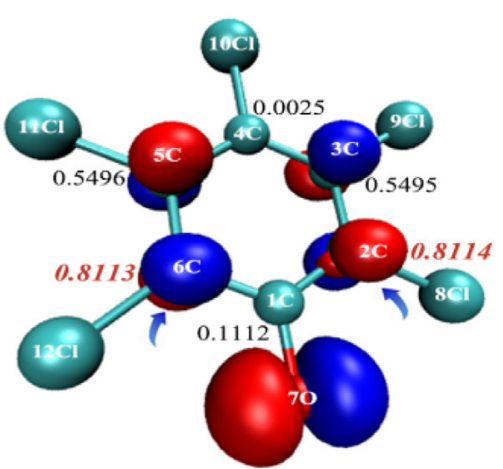

(a) $\mathrm{LUMO}$ of $\mathrm{PeCB}-\mathrm{O}^{\circ}$

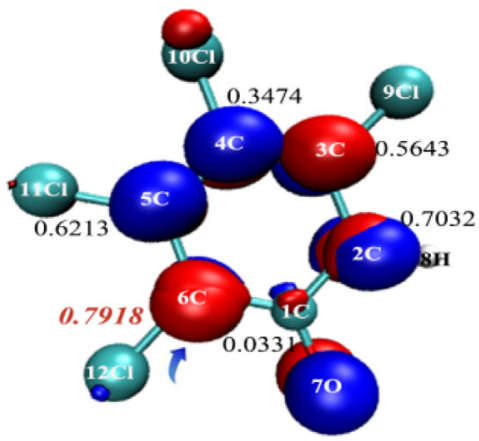

(c) LUMO of 2,3,4,5-TeCB-O•

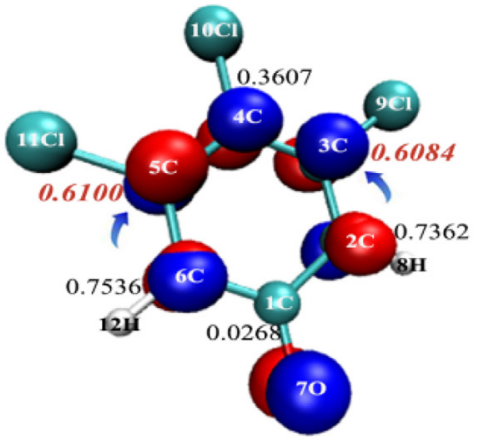

(e) LUMO of 3,4,5-TrCB-O•

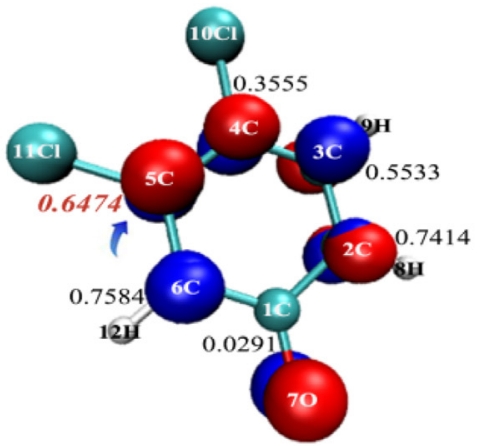

(g) LUMO of 3,4-DCB-O•

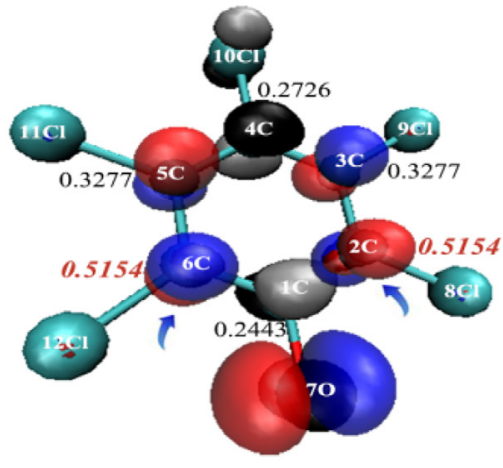

(b) $\mathrm{LUMO}+\mathrm{HOMO}$ of PeCB-O•

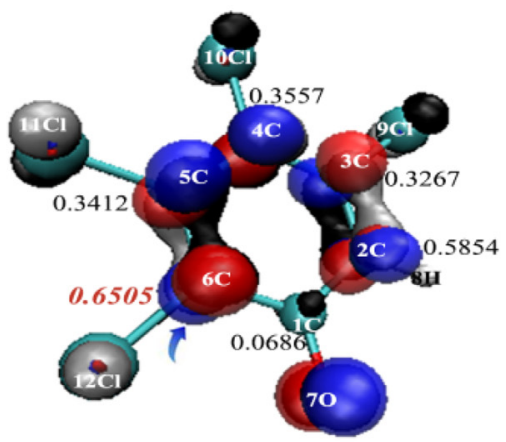

(d) $\mathrm{LUMO}+\mathrm{HOMO}$ of 2,3,4,5-TeCB-O*

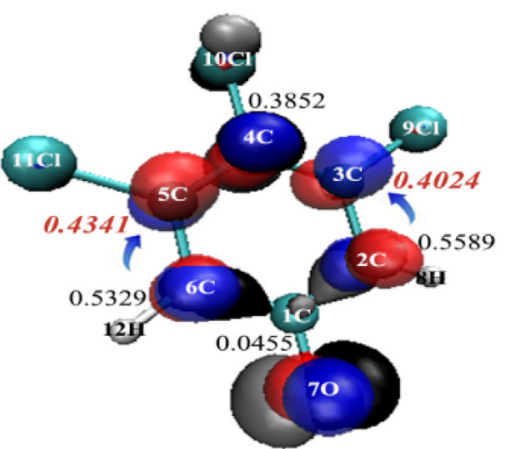

(f) $\mathrm{LUMO}+$ HOMO of 3,4,5-TrCB-O•

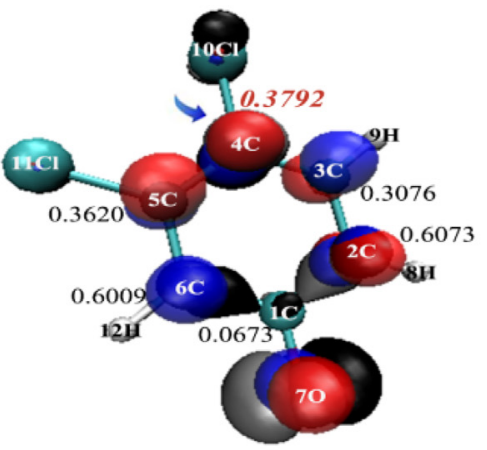

(h) LUMO + HOMO of 3,4-DCB-O•

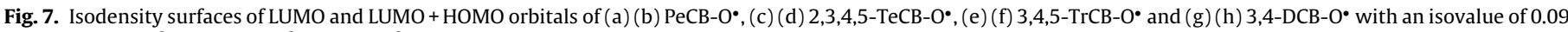

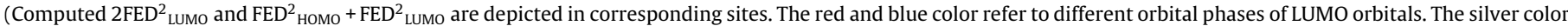

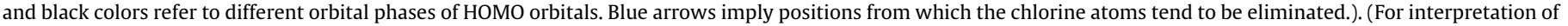
the references to colour in this figure legend, the reader is referred to the web version of this article.)

bon with the highest negative charge density (the lowest atomic charge), which has been viewed as the rule of thumb of reductive dechlorination pathways [67]. All of the atomic charges of carbon atoms in the dominant low-chlorinated radicals were calculated by methods of Mulliken population [68], Hirshfeld population [42,69] and MK ESP fitting charge [70].

Table 1 displays atomic charges of the major $\mathrm{CB}-\mathrm{O}^{\bullet}$ formed during the stepwise dechlorination. For PeCB-O $\mathrm{O}^{\bullet}$, atom $2(\mathrm{C})$ and 


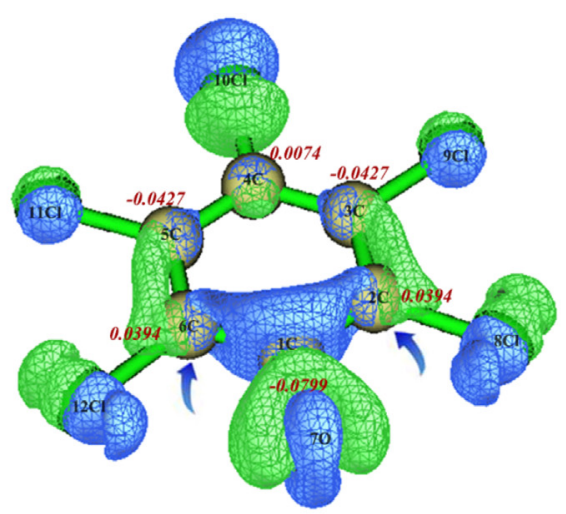

(a) $\mathrm{PeCB}-\mathrm{O}^{\bullet}$

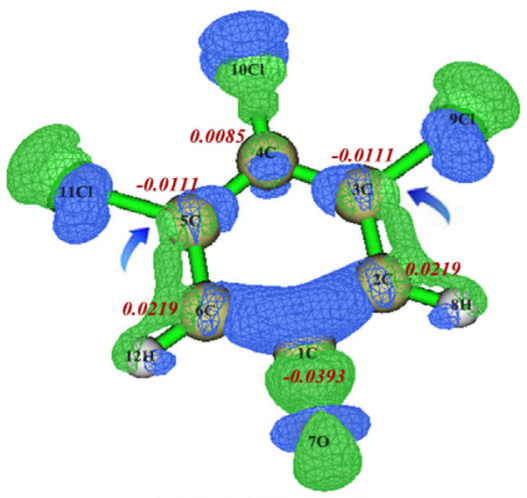

(c) $3,4,5-\operatorname{TrCB}-\mathrm{O}^{\bullet}$

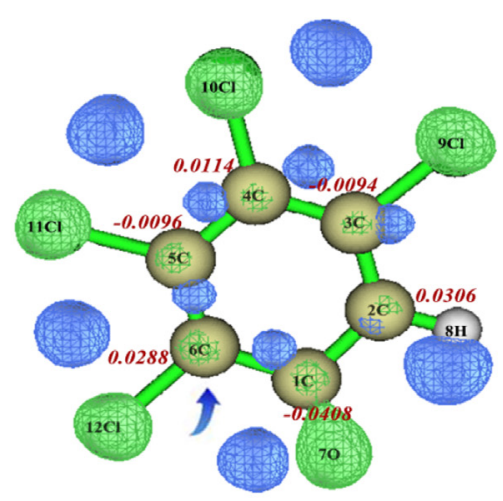

(b) 2,3,4,5-TeCB-O•

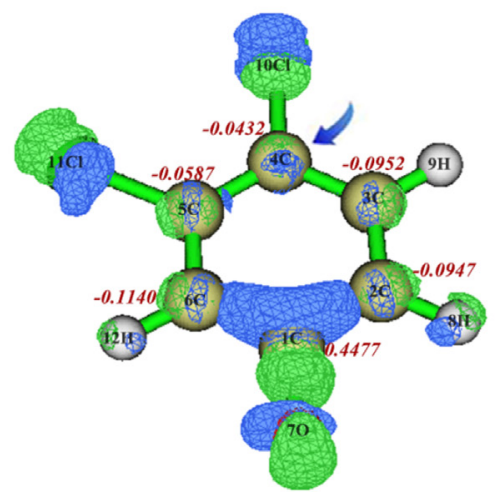

(d) 3,4-DCB-O•

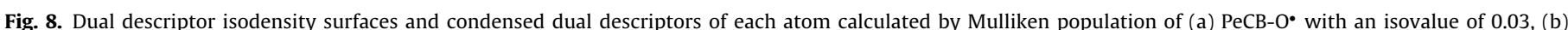

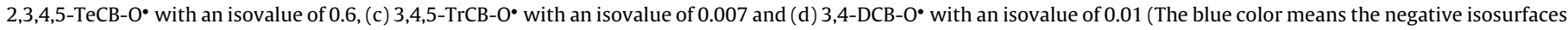

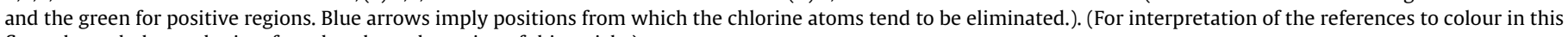
figure legend, the reader is referred to the web version of this article.)

6(C) possessed the lowest charges among the five substituent sites, thus the $\mathrm{Cl}$ on the sites of 2 and 6 are the most active in the radical, indicating that $2,3,4,5-\mathrm{TeCB}-\mathrm{O}^{\bullet}$ is the major tetrachlorinated product. Similarly, $\mathrm{Cl}$ atoms at the sites of $6,3 / 4$ and 4 are the relative active sites for $2,3,4,5-\operatorname{TrCB}-\mathrm{O}^{\bullet}, 3,4,5$ TrCB- $\mathrm{O}^{\bullet}$ and 3,4-DCB- $\mathrm{O}^{\bullet}$, resulting in the main intermediates of $3,4,5-\mathrm{TrCB}-\mathrm{O}^{\bullet}, 3,4-\mathrm{DCB}-\mathrm{O}^{\bullet}$ and $3-\mathrm{MCB}^{-} \mathrm{O}^{\bullet}$ for the trichlorinated, dichlorinated and monochlorinated isomers. Finally, the last chlorine would be removed and achieved the complete dechlorination. When samples were dissolved into hexane during the extraction procedure, $\mathrm{C}-\mathrm{O}$ bonds of $\mathrm{CB}-\mathrm{O}^{\bullet}$ would spilt and form corresponding chlorobenzenes by hydrogenation, which can be described as hydrodeoxgenation. Based on the naming rules of $\mathrm{CB}-\mathrm{O}^{\bullet}$ and chlorobenzene, serial numbers would change and the main contents should be 1,2,3,4-TeCB, 1,2,3-TrCB, 1,2-DCB and $\mathrm{MCB}$. Therefore, the main dechlorination route predicted by atomic charge can be depicted as $\mathrm{HCB} \rightarrow \mathrm{PeCB} \rightarrow 1,2,3,4-\mathrm{TeCB} \rightarrow 1,2,3-$ $\operatorname{TrCB} \rightarrow 1,2-\mathrm{DCB} \rightarrow \mathrm{MCB}$, agreed well with the experimental results shown in Fig. 1.

Moreover, Fig. 5(a-d) depicts changes of atomic charge during the dechlorination from PeCB to MCB by Mulliken analysis. The red color refers to the most negative charge while the green color for the most positive one. It can be seen that only the carbon atom linked to oxygen possessed positive charge, and carbon atoms substituted by chlorine hold more positive charges than other atoms linked to hydrogen. This might be because the electron attracting ability follows the order: oxygen > chlorine > hydrogen, and the strong electron attracting ability result in the positive charges of their linked atoms. As a consequence of the strong electron attracting ability, after eliminating one chlorine, the oxygen charge of
2,3,4,5-TeCB-O• was about 0.15 lower than that of $\mathrm{PeCB}-\mathrm{O}^{\bullet}$, shown in Fig. 5(a,b), while other atoms varied little. Therefore, the addition of oxygen into radicals would affect the charge distribution and then result in different regioselectivity compared to radicals without oxygen.

Electrostatic potential (ESP) is a significant feature to study the regioselectivity of dechlorination. The atom with more positive ESP is more susceptible to be a reactive site of reductive dechlorination. However, hydrogen atoms would lead to the maximum points deviate from the right locations, resulting in inappropriate determination of the reactive sites [44]. The internal charge separation (Pi) can be used as a substitution to illustrate the reaction route. $\mathrm{Pi}$, a parameter calculated in the ESP calculation process, is viewed as an indicator of charge separation. Negative charges around the oxygen atom lead to the relative deep ESP wells in the neighborhood, which might be active sites for dechlorination reaction. ESP distribution of the major $\mathrm{CB}-\mathrm{O}^{\bullet}$ formed during the stepwise dechlorination is shown in Fig. 6(a-d). It could be found in Fig. 6(a) that the ortho-positions of $\mathrm{PeCB}-\mathrm{O}^{\bullet}$, ortho-position of $2,3,4,5-$ TeCB-O• meta-positions of 3,4,5-TrCB-O ${ }^{\bullet}$ and meta-position of 3,4 -DCB-O hold the maximum Pi values of corresponding radicals. Therefore, the dominant low-chlorinated isomers should be $\mathrm{PeCB}$, 1,2,3,4-TeCB, 1,2,3-TrCB and 1,2-DCB, fitting well with the results measured by GC-MS.

FMO theory describes chemical reactivity to interactions between the highest occupied molecular orbital (HOMO) of one species and the lowest unoccupied molecular orbital (LUMO) of the other. The direct reductive dechlorination usually occurs at the atoms with higher $2 \mathrm{FED}^{2}{ }_{\text {LUMO, while the radical attack }}$ can more probably take place at sites with higher values of 

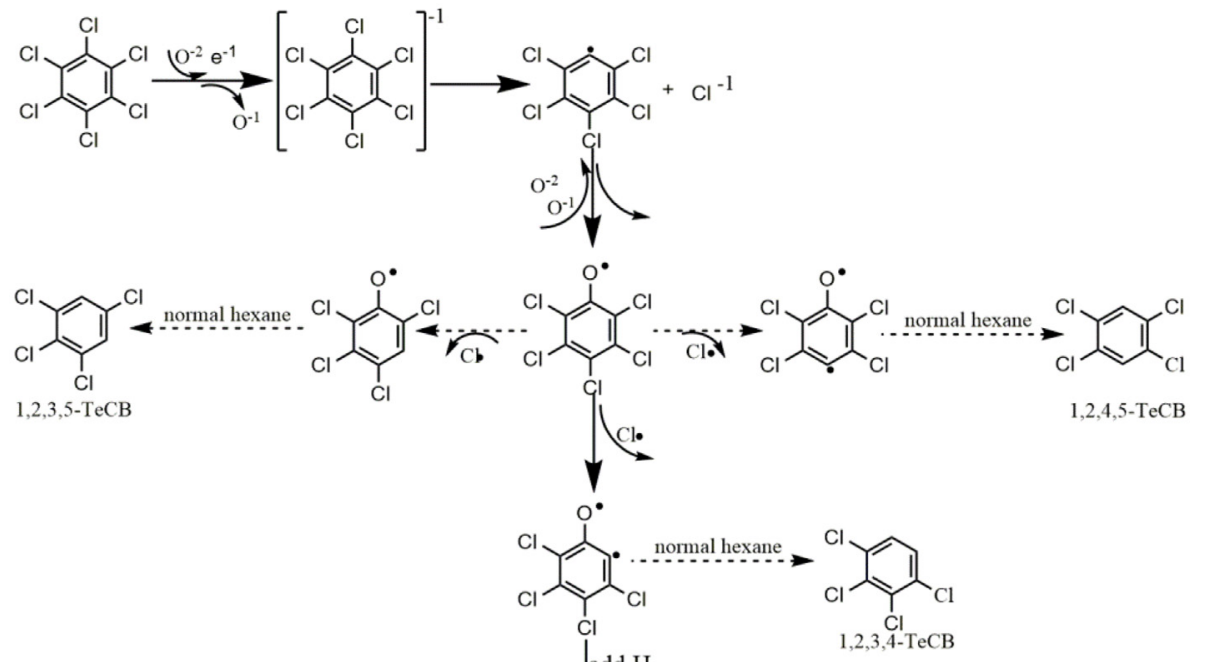

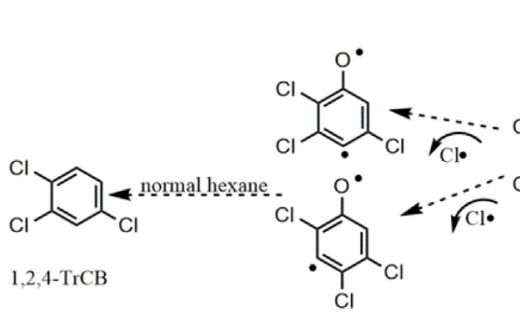<smiles>[124H]</smiles><smiles>ClC1=C(Cl)C2=C(CCC2)C1</smiles>

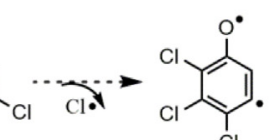

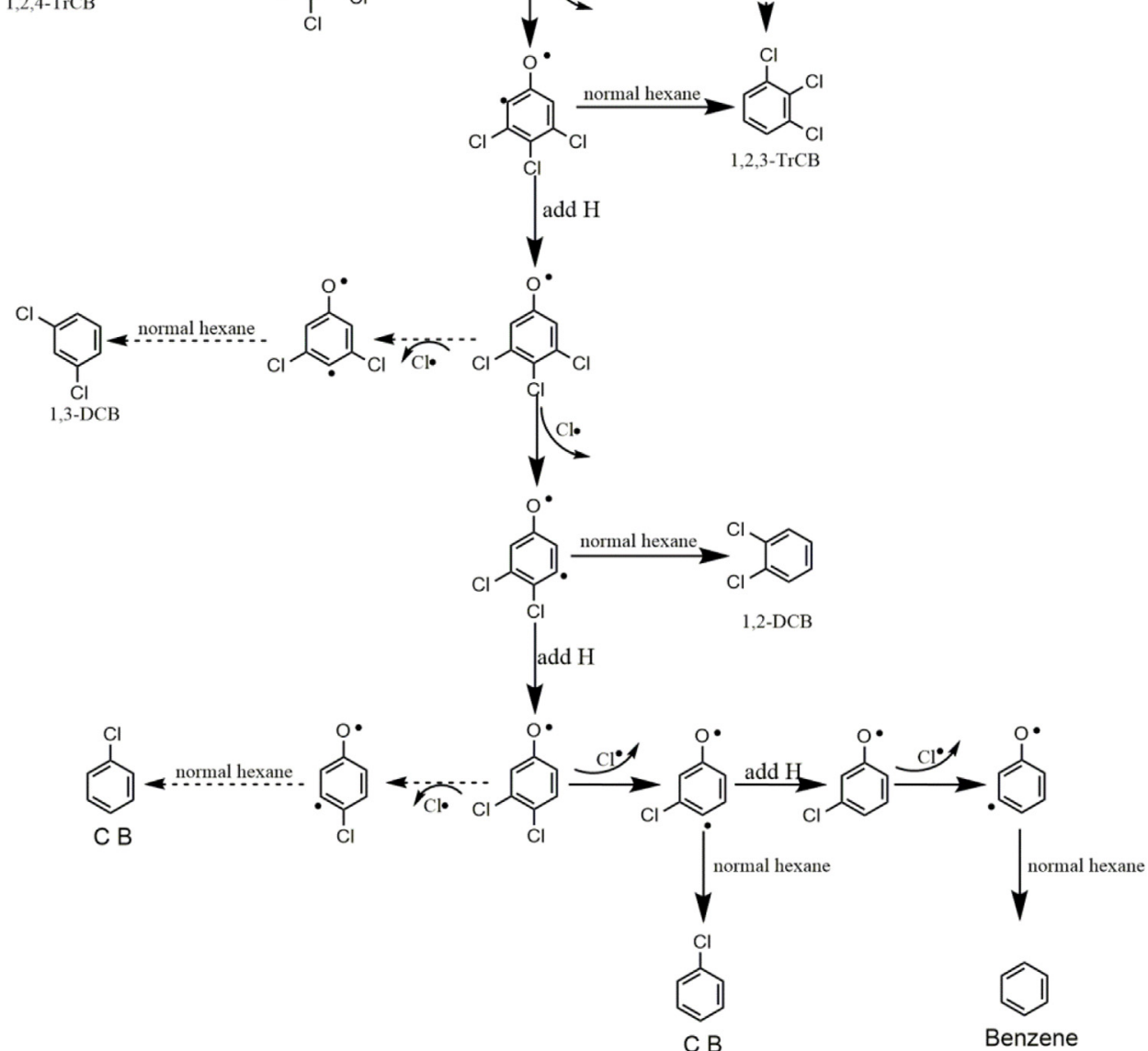

Fig. 9. Step-wise dechlorination mechanism based on $\mathrm{CB}-\mathrm{O} \bullet$ radicals (The solid line indicates the main pathway.).

$\mathrm{FED}^{2}{ }_{\text {HOMO }}+\mathrm{FED}^{2}$ LUMO [71]. The isodensity surfaces of LUMO and $\mathrm{LUMO}+\mathrm{HOMO}$ of $\mathrm{CB}-\mathrm{O}^{\bullet}$ are shown in Fig. $7(\mathrm{a}-\mathrm{d})$. Values of $2 \mathrm{FED}^{2}{ }_{\text {LUMO }}$ and $\mathrm{FED}^{2}{ }_{\text {HOMO }}+\mathrm{FED}^{2}{ }_{\text {LUMO }}$ for each carbon atom are also supplied. For $\mathrm{PeCB}-\mathrm{O}^{\bullet}, 2,3,4,5-\mathrm{TeCB}-\mathrm{O}^{\bullet}$ and 3,4,5-TrCB-O ${ }^{\bullet}$, both $2 \mathrm{FED}^{2}{ }_{\text {LUMO }}$ and $\mathrm{FED}^{2}{ }_{\mathrm{HOMO}}+\mathrm{FED}^{2}{ }_{\text {LUMO }}$ indicated the same results that $1,2,3,4-\mathrm{TeCB}, 1,2,3-\operatorname{TrCB}$ and 1,2-DCB were the main intermediates. Whereas, as shown in Fig. $7(\mathrm{~g}, \mathrm{~h}), 2 \mathrm{FED}^{2}{ }_{\text {LUMO }}$ revealed that meta-position is the most active sites for 3,4-DCB-O•, while $\mathrm{FED}^{2}{ }_{\mathrm{HOMO}}+\mathrm{FED}^{2}$ LUMo implied the para-position. Compared with the atomic charge analysis, $\mathrm{FED}^{2}{ }_{\mathrm{HOMO}}+\mathrm{FED}^{2}{ }_{\text {LUMO }}$ is more appropri- 
Table 2

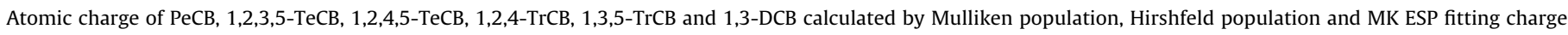
analysis.

\begin{tabular}{|c|c|c|c|c|}
\hline Structure & Atom & Mulliken & Hirshfeld & MK ESP \\
\hline & 1 & -0.1215 & -0.0441 & -0.0555 \\
\hline & 2 & -0.0660 & 0.0235 & -0.0016 \\
\hline & 3 & -0.0791 & 0.0126 & 0.0773 \\
\hline & 4 & -0.0791 & 0.0174 & 0.0119 \\
\hline & 5 & -0.0791 & 0.0126 & 0.0773 \\
\hline & 6 & -0.0660 & 0.0235 & -0.0038 \\
\hline & 1 & -0.1224 & -0.0462 & -0.0345 \\
\hline & 2 & -0.0602 & 0.0324 & -0.0195 \\
\hline & 3 & -0.1224 & -0.0047 & -0.0345 \\
\hline & 4 & -0.0702 & 0.0267 & -0.0161 \\
\hline & 5 & -0.0823 & 0.0105 & 0.1193 \\
\hline & 6 & -0.0702 & 0.0267 & -0.0161 \\
\hline & 1 & -0.0125 & -0.0411 & -0.0942 \\
\hline & 2 & -0.0696 & 0.0219 & 0.0463 \\
\hline & 3 & -0.0696 & 0.0219 & 0.0463 \\
\hline & 4 & -0.0125 & -0.0411 & -0.0942 \\
\hline & 5 & -0.0696 & 0.0219 & 0.0449 \\
\hline & 6 & -0.0696 & 0.0219 & 0.0449 \\
\hline & 1 & -0.1246 & -0.0334 & -0.1314 \\
\hline & 2 & -0.1217 & -0.0383 & -0.0845 \\
\hline & 3 & -0.0626 & 0.0294 & 0.0129 \\
\hline & 4 & -0.1255 & -0.0448 & -0.0545 \\
\hline & 5 & -0.0719 & 0.0237 & 0.0383 \\
\hline & 6 & -0.0732 & 0.0182 & 0.0703 \\
\hline & 1 & -0.1240 & -00492 & -0.0182 \\
\hline & 2 & -0.0646 & 0.0354 & -0.0199 \\
\hline & 3 & -0.1240 & -00492 & -0.0160 \\
\hline & 4 & -0.0646 & 0.0354 & -0.0214 \\
\hline & 5 & -0.1240 & -00492 & -0.0160 \\
\hline & 6 & -0.0646 & 0.0354 & -0.0199 \\
\hline & 1 & -0.1260 & -0.0272 & -0.1751 \\
\hline & 2 & -0.1249 & -0.0440 & -0.0603 \\
\hline & 3 & -0.0645 & 0.0307 & 0.0139 \\
\hline & 4 & -0.1249 & -0.0492 & -0.0226 \\
\hline & 5 & -0.0645 & 0.0307 & 0.0127 \\
\hline & 6 & -0.1249 & -0.0440 & -0.0603 \\
\hline
\end{tabular}

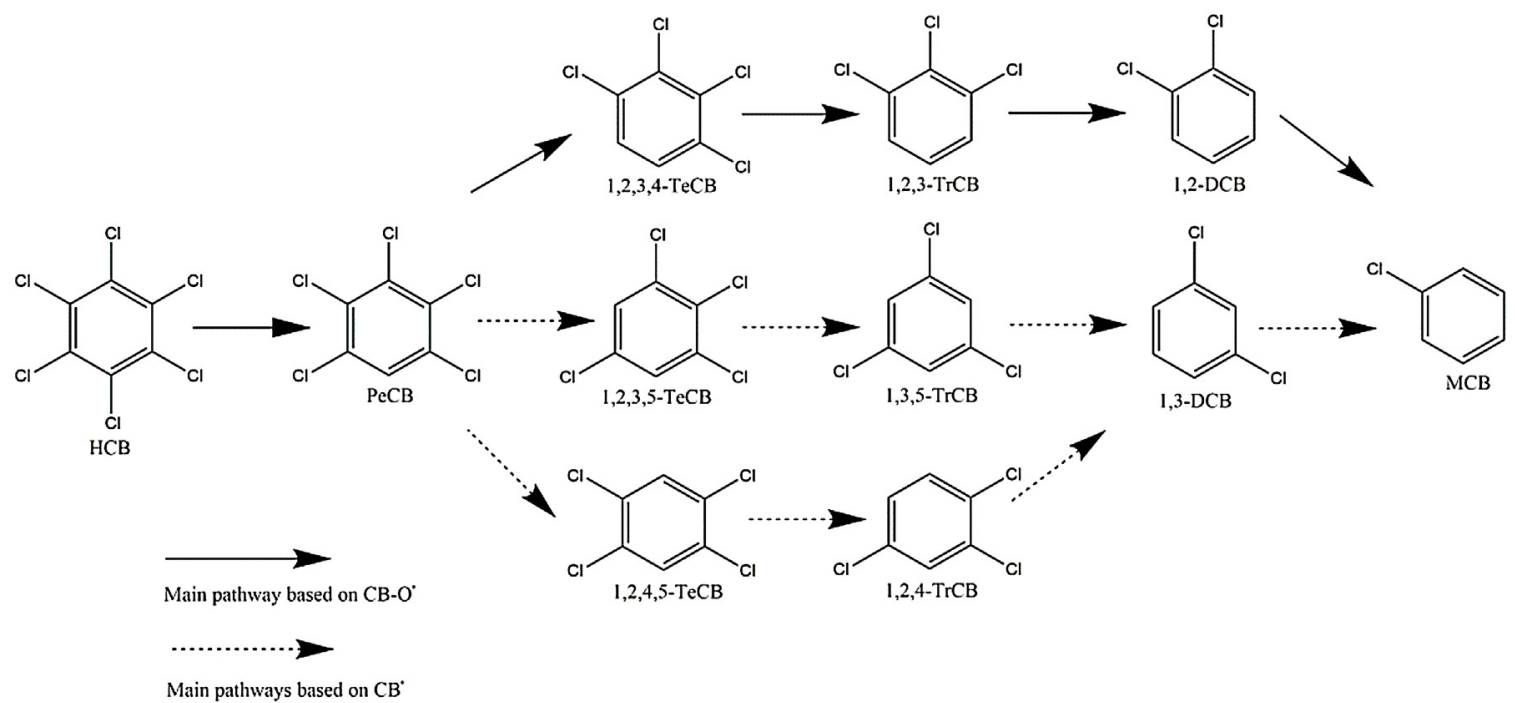

Fig. 10. Comparison of the primary $\mathrm{CB}-\mathrm{O}^{\bullet}$ based pathway and the main pathways with $\mathrm{CB}^{\bullet}$.

ate for our reaction, and this discrepancy might reveal that radical attack is the dechlorination pathway for our reaction system.

It was generally proposed in the dual descriptor analysis that the position with higher value contributes more to positive regions and LUMO and is much easier for dechlorination [41,72]. The condensed dual descriptors of each atom were calculated by Mulliken population method in this study. As shown in Fig. 8(a-d), dual descriptor analysis exhibited excellent reproducibility of experimental results on the dechlorination of PeCB-O• ${ }^{\bullet}, 2,3,4,5-\mathrm{TeCB}-\mathrm{O}^{\bullet}, 3,4,5-\mathrm{TrCB}-\mathrm{O}^{\bullet}$ and $3,4-\mathrm{DCB}-\mathrm{O}^{\bullet}$, consistent with the experimental results. In general, all of the four quantum chemical descriptors can precisely reveal the dechlorination route of $\mathrm{CB}-\mathrm{O}^{\bullet}$.

Based on both the experimental results and quantum chemical calculations, the $\mathrm{CB}-\mathrm{O}^{\bullet}$ based stepwise dechlorination mechanism for the MCT of HCB was proposed and shown in Fig. 9. Herein, the dechlorination and hydrogenation was described, however, 
dehalogenation is not the only process occured during milling. The organic radicals might also react with other organic species. This is the pathway lead to polymerization and final carbonization. Degradation of the organic structure is also another process and the main responsible for the generation of amorphous/graphitic carbon [27]. This intriguing problem will be elucidated through the unite method of experiments and quantum chemical calculations in the near future.

\subsection{Impacts of different radical reactions on the dechlorination of $H C B$}

Considering the complexity of MCT process and radical reactions, $\mathrm{CB}^{\bullet}$ based dechlorination might be another pathway of HCB's decomposition. If some of the $\mathrm{PeCB}{ }^{\bullet}$ have no chance to react with $\mathrm{O}^{2-}$ after chlorine expulsion induced by the capture of a trapped electron on the $\mathrm{Al}_{2} \mathrm{O}_{3}$ or $\mathrm{Al}$ surface, then the dechlorination will proceed on with $\mathrm{PeCB}^{\bullet}, \mathrm{TeCB}^{\bullet}, \mathrm{TrCB}^{\bullet}$ and $\mathrm{DCB}^{\bullet}$, similar to the photocatalytic degradation mechanism [73]. However, $\mathrm{CB}^{\bullet}$ based photodegradation of $\mathrm{HCB}$ demonstrates that meta- $\mathrm{Cl}$ and para- $\mathrm{Cl}$ are the easiest sites to be removed [73]. This conspicuous discrepancy implies a vast difference in the active sites for dechlorination between $\mathrm{CB}-\mathrm{O}^{\bullet}$ and $\mathrm{CB}^{\bullet}$, showing that $\mathrm{CB}^{\bullet}$ based process is only a minor pathway for HCB's decomposition in the MCT.

Mulliken population, Hirshfeld population and MK ESP fitting charge of PeCB, 1,2,3,5-ТeCB, 1,2,4,5-ТeCB, 1,2,4-TrCB, 1,3,5-TrCB and $1,3-\mathrm{DCB}$ were also calculated to theoretically elucidate the $\mathrm{CB} \bullet$ based dechloriantion routes (given in Table 2). Except MK ESP fitting charge, atomic charges of the meta-positions (atom $3(\mathrm{C})$ and $5(\mathrm{C})$ ) were the lowest and the para-C (atom 4(C)) hold the same Mulliken charge with the meta-positions. This analysis is consistent with the main experimental route that 1,2,4,5-TeCB and 1,2,3,5TeCB were the main TeCBs. For $1,2,3,5-\mathrm{TeCB}$, atom $5(\mathrm{C})$ possessed the lowest charge among the four substituent sites, thus $1,3,5-\operatorname{TrCB}$ might be its primary $\operatorname{TrCB}$ product. $1,2,4-\mathrm{TeCB}$ is the single $\operatorname{TrCB}$ product of $1,2,4,5-\mathrm{TeCB}$ due to the symmetry and 1.3-DCB is the main product for $1,2,4-\mathrm{TeCB}$. In addition, $1,2,3,5-\mathrm{TeCB}$ is preferred to produce $1,3,5-\operatorname{TrCB}$ with $1,3-\mathrm{DCB}$ as the sole $\mathrm{DCB}$ product. The main $\mathrm{CB}^{\bullet}$ based dechlorination routes were predicted as $\mathrm{HCB} \rightarrow$ $\mathrm{PeCB} \rightarrow 1,2,3,5-\mathrm{TeCB} / 1,2,4,5-\mathrm{TeCB} \rightarrow 1,3,5-\mathrm{TrCB} / 1,2,4-\mathrm{TrCB} \rightarrow 1,3-$ $\mathrm{DCB} \rightarrow \mathrm{MCB}$, as depicted in Fig. 10, dissimilar to the primary $\mathrm{CB}-\mathrm{O}^{\bullet}$ based pathway. Both of the dominant intermediates and quantum chemical descriptor analysis confirms that dechlorination pathway based on $\mathrm{CB}-\mathrm{O}^{\bullet}$ prevails in the MCT process.

\section{Conclusions}

In this paper, the mechanochemical mechanism of rapid dechlorination of HCB was studied by both experiments and quantum chemical calculations. The step-wise dechlorination pathways of $\mathrm{HCB}$ in the MCT process was proposed and testified by quantum chemical descriptor analysis. The main results can be concluded as follows:

(1) $\mathrm{HCB}$ can be degraded in the MCT process with $\mathrm{Al}$ and $\mathrm{Al}_{2} \mathrm{O}_{3}$ as co-milling reagents in about $60 \mathrm{~min}$. Characterization of ESR, FTIR and XPS testified that the dechlorination route of $\mathrm{HCB}$ mainly proceed via the routes deduced by $\mathrm{CB}-\mathrm{O}^{\bullet}$ radials.

(2) Thermodynamic calculations and quantum chemical descriptors successfully predicted the dechlorination pathways of $\mathrm{HCB}$ in the MCT process.

(3) Comparisons of the mechanochemical and photochemical dechlorination of HCB showed that the intermediate products are different in these two processes. The former is based on $\mathrm{CB}-\mathrm{O}^{\bullet}$, while the latter is based on $\mathrm{CB}^{\bullet}$.

\section{Acknowledgments}

This work was financially supported by the National Natural Science Foundation of China (21677162 and 91645126).

\section{Appendix A. Supplementary data}

Supplementary data associated with this article can be found, in the online version, at http://dx.doi.org/10.1016/j.jhazmat.2017.03. 022 .

\section{References}

[1] J.F. Fernandez-Bertran, Mechanochemistry: an overview, Pure Appl. Chem. 71 (1999) 581-586.

[2] A. Nasser, U. Mingelgrin, Mechanochemistry: a review of surface reactions and environmental applications, Appl. Clay Sci. 67-68 (2012) 141-150.

[3] H.N. Stein, Tribochemistry, Adv. Colloid Interface Sci. 21 (1984) 329-330.

[4] V.V. Boldyrev, K. Tkacova, Mechanochemistry of solids: past, present, and prospects, J. Mater. Synth. Process. 8 (2000) 121-132.

[5] V.V. Boldyrev, Mechanochemistry and mechanical activation of solids, Mater. Sci. Forum 225-227 (1996) 511-520.

[6] X. Guo, D. Xiang, G. Duan, P. Mou, A review of mechanochemistry applications in waste management, Waste Manag. 30 (2010) 4-10.

[7] M.-M. Wang, C.-C. Zhang, F.-S. Zhang, An environmental benign process for cobalt and lithium recovery from spent lithium-ion batteries by mechanochemical approach, Waste Manage. 51 (2016) 239-244.

[8] S. Montinaro, A. Concas, M. Pisu, G. Cao, Remediation of heavy metals contaminated soils by ball milling, in: C. Merli, S. Pierucci, J.J. Klemes (Eds.), Bosicon 2012: 3rd International Conference on Contaminated Sites Remediation (2012) 187-192.

[9] Q. Tan, J. Li, Recycling metals from wastes: a novel application of mechanochemistry, Environ. Sci. Technol. 49 (2015) 5849-5861.

[10] S.L. James, C.J. Adams, C. Bolm, D. Braga, P. Collier, T. Friscic, F. Grepioni, K.D.M Harris, G. Hyett, W. Jones, A. Krebs, J. Mack, L. Maini, A.G. Orpen, I.P. Parkin, W.C. Shearouse, J.W. Steed, D.C. Waddell, Mechanochemistry: opportunities for new and cleaner synthesis, Chem. Soc. Rev. 41 (2012) 413-447.

[11] J. Huot, D.B. Ravnsbaek, J. Zhang, F. Cuevas, M. Latroche, T.R. Jensen, Mechanochemical synthesis of hydrogen storage materials, Prog. Mater. Sci. 58 (2013) 30-75.

[12] A. Fischer, C. Ney, G. Kickelbick, Synthesis of surface-functionalized titania particles with organophosphorus coupling agents by reactive milling, Eur. J. Inorg. Chem. 2013 (2013) 5701-5707.

[13] S.A. Rowlands, A.K. Hall, P.G. McCormick, R. Street, R.J. Hart, G.F. Ebell, P. Donecker, Destruction of toxic materials, Nature 367 (1994) 223.

[14] A.K. Hall, J.M. Harrowfield, R.J. Hart, P.G. McCormick, Mechanochemical reaction of DDT with calcium oxide, Environ. Sci. Technol. 30 (1996) 3401-3407.

[15] K. Zhang, J. Huang, G. Yu, Q. Zhang, S. Deng, B. Wang, Destruction of perfluorooctane sulfonate (PFOS) and perfluorooctanoic acid (PFOA) by ball milling, Environ. Sci. Technol. 47 (2013) 6471-6477.

[16] M. Aresta, A. Dibenedetto, T. Pastore, Mechanochemistry: an old technology with new applications to environmental issues. Decontamination of polychlorobiphenyl-contaminatecl soil by high-energy milling in the solid state with ternary hydrides, Environ. Chem.: Green Chem. Pollut. Ecosyst. (2005) 553-559

[17] M.K. Beyer, H. Clausen-Schaumann, Mechanochemistry: the mechanical activation of covalent bonds, Chem. Rev. 105 (2005) 2921-2948.

[18] M.D.R. Pizzigallo, A. Napola, M. Spagnuolo, P. Ruggiero, Mechanochemical removal of organo-chlorinated compounds by inorganic components of soil, Chemosphere 55 (2004) 1485-1492.

[19] Q. Zhang, F. Saito, T. Ikoma, S. Tero-Kubota, K. Hatakeda, Effects of quartz addition on the mechanochemical dechlorination of chlorobiphenyl by using CaO, Environ. Sci. Technol. 35 (2001) 4933-4935.

[20] Y. Nomura, K. Fujiwara, A. Terada, S. Nakai, M. Hosomi, Mechanochemical degradation of gamma-hexachlorocyclohexane by a planetary ball mill in the presence of CaO, Chemosphere 86 (2012) 228-234.

[21] Y. Nomura, S. Nakai, M. Hosomi, Elucidation of degradation mechanism of dioxins during mechanochemical treatment, Environ. Sci. Technol. 39 (2005) 3799-3804

[22] Y. Yu, J. Huang, W. Zhang, K. Zhang, S. Deng, G. Yu, Mechanochemical destruction of mirex co-ground with iron and quartz in a planetary ball mill, Chemosphere 90 (2013) 1729-1735.

[23] P. Di Leo, M.D.R. Pizzigallo, V. Ancona, F. Di Benedetto, E. Mesto, E. Schingaro, G. Ventruti, Mechanochemical degradation of pentachlorophenol onto birnessite, J. Hazard. Mater. 244-245 (2013) 303-310.

[24] I.W. Nah, K.-Y. Hwang, Y.-G. Shul, Effect of metal and glycol on mechanochemical dechlorination of polychlorinated biphenyls (PCBs), Chemosphere 73 (2008) 138-141.

[25] W. Zhang, H. Wang, J. Huang, M. Yu, F. Wang, L. Zhou, G. Yu, Acceleration and mechanistic studies of the mechanochemical dechlorination of HCB with iron powder and quartz sand, Chem. Eng. J. 239 (2014) 185-191. 
[26] T. Ikoma, Q.W. Zhang, F. Saito, K. Akiyama, S. Tero-Kubota, T. Kato, Radicals in the mechanochemical dechlorination of hazardous organochlorine compounds using CaO nanoparticles, Bull. Chem. Soc. Jpn. 74 (2001) 2303-2309.

[27] K. Zhang, J. Huang, W. Zhang, Y. Yu, S. Deng, G. Yu, Mechanochemical degradation of tetrabromobisphenol A: Performance, products and pathway, J. Hazard. Mater. 243 (2012) 278-285.

[28] S. Andini, A. Bolognese, D. Formisano, M. Manfra, F. Montagnaro, L. Santoro Mechanochemistry of ibuprofen pharmaceutical, Chemosphere 88 (2012) $548-553$.

[29] T. Zhang, J. Huang, W. Zhang, Y. Yu, S. Deng, B. Wang, G. Yu, Coupling the dechlorination of aqueous 4-CP with the mechanochemical destruction of solid PCNB using Fe-Ni-SiO 2 , J. Hazard. Mater. 250 (2013) 175-180.

[30] K. Nakayama, Triboemission of electrons, ions, and photons from diamondlike carbon films and generation of tribomicroplasma, Surf. Coat. Technol. 188-189 (2004) 599-604.

[31] Y. Tanaka, Q.W. Zhang, F. Saito, T. Koma, S. Tero-Kubota, Dependence of mechanochemically induced decomposition of mono-chlorobiphenyl on the occurrence of radicals, Chemosphere 60 (2005) 939-943.

[32] M. Hasegawa, T. Ogata, M. Sato, Mechano-radicals produced from ground quartz and quartz glass, Powder Technol. 85 (1995) 269-274.

[33] S. Arulmozhiraja, M. Morita, Electron affinities and reductive dechlorination of toxic polychlorinated dibenzofurans: a density functional theory study, J. Phys. Chem. A 108 (2004) 3499-3508.

[34] H. Fueno, K. Tanaka, S. Sugawa, Theoretical study of the dechlorination reaction pathways of octachlorodibenzo-p-dioxin, Chemosphere 48 (2002) $771-778$.

[35] P.M. Esteves, J.W.D. Carneiro, S.P. Cardoso, A.G.H. Barbosa, K.K. Laali, G. Rasul, G.K.S. Prakash, G.A. Olah, Unified mechanistic concept of electrophilic aromatic nitration: convergence of computational results and experimental data, J. Am. Chem. Soc. 125 (2003) 4836-4849.

[36] Vikas Reenu, Exploring the role of quantum chemical descriptors in modeling acute toxicity of diverse chemicals to Daphnia magna, J. Mol. Graph. Modell. 61 (2015) 89-101.

[37] G.-N. Lu, Z. Dang, D.E. Fennell, W. Huang, Z. Li, C.-O. Liu, Rules of thumb for assessing reductive dechlorination pathways of PCDDs in specific systems, J. Hazard. Mater. 177 (2010) 1145-1149.

[38] K. Fukui, Theory of Orientation and Stereoselection, Springer Berlin Heidelberg, Berlin, Heidelberg, 1970.

[39] P. Sjoberg, P. Politzer, Use of the electrostatic potential at the molecular-surface to interpret and predict nucleophilic processes, J. Phys. Chem. 94 (1990) 3959-3961.

[40] R.G. Parr, W. Yang, Density functional approach to the frontier-electron theory of chemical reactivity, J. Am. Chem. Soc. 106 (1984) 4049-4050.

[41] C. Morell, A. Grand, A. Toro-Labbé, New dual descriptor for chemical reactivity, J. Phys. Chem. A 109 (2005) 205-212.

[42] S. Saha, R.K. Roy, P.W. Ayers, Are the Hirshfeld and Mulliken population analysis schemes consistent with chemical intuition? Int. J. Quantum Chem. 109 (2009) 1790-1806

[43] P.C. Mishra, R.D. Tewari, Fixed closest distance of approach dipole potential mapping: an effective alternative to the monopole isopotential approach, Int. J. Quantum Chem. 32 (1987) 181-191

[44] J. Cao, Q. Ren, F. Chen, T. Lu, Comparative study on the methods for predicting the reactive site of nucleophilic reaction, Sci. China Chem. 58 (2015) 1845-1852.

[45] R. Santamaria, G. Cocho, L. Corona, E. Gonzalez, Molecular electrostatic potentials and Mulliken charge populations of DNA mini-sequences, Chem. Phys. 227 (1998) 317-329.

[46] E.V. Rokhina, R.P.S. Suri, Application of density functional theory (DFT) to study the properties and degradation of natural estrogen hormones with chemical oxidizers, Sci. Total Environ. 417 (2012) 280-290.

[47] Z. Demircioglu, C.A. Kastas, O. Buyukgungor, Theoretical analysis (NBO, NPA Mulliken Population Method) and molecular orbital studies (hardness, chemical potential, electrophilicity and Fukui function analysis) of (E)-2-((4-hydroxy-2-methylphenylimino)methyl)-3-methoxyphenol, J. Mol. Struct. 1091 (2015) 183-195.

[48] L. Zhang, M. Zheng, W. Liu, B. Zhang, G. Su, A method for decomposition of hexachlorobenzene by $\gamma$-alumina, J. Hazard. Mater. 150 (2008) 831-834.

[49] A. Khaleel, B. Dellinger, FTIR investigation of adsorption and chemical decomposition of $\mathrm{CCl}_{4}$ by high surface-area aluminum oxide, Environ. Sci. Technol. 36 (2002) 1620-1624.

[50] Sunhee Kim, Oleg Byl, John T. Yates, Jr, The adsorption of triethylenediamine on $\mathrm{Al}_{2} \mathrm{O}_{3}$-II: Hydrogen bonding to Al-OH groups, J. Phys. Chem. B 109 (2005) 3507-3511.
[51] B.D. Flockhart, Electron-transfer at alumina surfaces. Part 1.-Electron-acceptor properties of aluminas, Trans. Faraday Soc. 62 (1966) 730-740.

[52] Y. Ren, S. Kang, J. Zhu, Mechanochemical degradation of hexachlorobenzene using $\mathrm{Mg} / \mathrm{Al}_{2} \mathrm{O}_{3}$ as additive, J. Mater. Cycles Waste Manage. 17 (2015) 607-615.

[53] M.J. Frisch, G.W. Trucks, H.B. Schlegel, G.E. Scuseria, M.A. Robb, J.R Cheeseman, G. Scalmani, V. Barone, B. Mennucci, G.A. Petersson, H. Nakatsuji, M. Caricato, X. Li, H.P. Hratchian, A.F. Izmaylov, J. Bloino, G. Zheng, J.L. Sonnenberg, M. Hada, M. Ehara, K. Toyota, R. Fukuda, J. Hasegawa, M. Ishida, T. Nakajima, Y. Honda, O. Kitao, H. Nakai, T. Vreven, J.A. Montgomery, Jr., J.E. Peralta, F. Ogliaro, M. Bearpark, J.J. Heyd, E. Brothers, K.N. Kudin, V.N. Staroverov, T. Keith, R. Kobayashi, J. Normand, K. Raghavachari, A. Rendell, J.C. Burant, S.S. Iyengar, J. Tomasi, M. Cossi, N. Rega, J.M. Millam, M. Klene, J.E. Knox, J.B. Cross, V. Bakken, C. Adamo, J. Jaramillo, R. Gomperts, R.E. Stratmann, O. Yazyev, A.J. Austin, R. Cammi, C. Pomelli, J.W. Ochterski, R.L. Martin, K. Morokuma, V.G. Zakrzewski, G.A. Voth, P. Salvador, J.J. Dannenberg, S. Dapprich, A.D. Daniels, O. Farkas, J.B. Foresman, J.V. Ortiz, J. Cioslowski, D.J. Fox, Gaussian 09, Revision D.01, Gaussian, Inc, Wallingford, CT, 2013.

[54] C.T. Lee, W.T. Yang, R.G. Parr, Development of the Colle-Salvetti correlation-energy formula into a functional of the electron-density, Phys. Rev. B 37 (1988) 785-789.

[55] D. Feller, The role of databases in support of computational chemistry calculations, J. Comput. Chem. 17 (1996) 1571-1586.

[56] K.L. Schuchardt, B.T. Didier, T. Elsethagen, L. Sun, V. Gurumoorthi, J. Chase, J. Li, T.L. Windus, Basis set exchange: a community database for computational sciences, J. Chem. Inf. Model. 47 (2007) 1045-1052.

[57] J.J. Fifen, Thermodynamics of the electron revisited and generalized, J. Chem. Theory Comput. 9 (2013) 3165-3169.

[58] T. Lu, F.W. Chen, Multiwfn: a multifunctional wavefunction analyzer, J. Comput. Chem. 33 (2012) 580-592.

[59] G. Kaupp, Mechanochemistry: the varied applications of mechanical bond-breaking, CrystEngComm 11 (2009) 388-403.

[60] Y. Tanaka, Q. Zhang, F. Saito, Mechanochemical dechlorination of trichlorobenzene on oxide surfaces, J. Phys. Chem. B 107 (2003) 11091-11097.

[61] T.H. Ballinger, J.T. Yates, Interaction and catalytic decomposition of 1,1,1-trichloroethane on high surface area alumina. An infrared spectroscopic study, J. Phys. Chem. 96 (1992) 1417-1423.

[62] L. Zhang, M. Zheng, B. Zhang, G. Su, Investigation of the decomposition mechanism of hexachlorobenzene on gamma- $\mathrm{Al}_{2} \mathrm{O}_{3}$, Environ. Technol. 33 (2012) 1945-1951.

[63] D. Lin-Vien, N.B. Colthup, W.G. Fateley, J.G. Grasselli, The Handbook of Infrared and Raman Characteristic Frequencies of Organic Molecules, Academic Press, San Diego, 1991.

[64] H.B. Yin, Y. Wada, T. Kitamura, S. Yanagida, Photoreductive dehalogenation of halogenated benzene derivatives using $\mathrm{ZnS}$ or $\mathrm{CdS}$ nanocrystallites as photocatalysts, Environ. Sci. Technol. 35 (2001) 227-231.

[65] S.Y. Lu, Q.L. Wang, D. Wu, X.D. Li, J.H. Yan, Photocatalytic decomposition of hexachlorobenzene on nano-titanium dioxide films-Experimental study and mechanistic considerations, Environ. Progress Sustain. Energy 32 (2013) 458-464.

[66] F.L. Hirshfeld, Bonded-atom fragments for describing molecular charge densities, Theor Chim acta 44 (1977) 129-138.

[67] B.-D. Lee, M.-J. Lee, Prediction of hydroxyl substitution site(s) of phenol, monochlorophenols and 4-chloronitrobenzene by atomic charge distribution calculations, Bull. Korean Chem. Soc. 30 (2009) 787-790.

[68] R.S. Mulliken, Electron population analysis on LCAO-MO molecular wave functions.1, J. Chem. Phys. 23 (1955) 1833-1840.

[69] F.L. Hirshfeld, Bonded-atom fragments for describing molecular charge-densities, Theor. Chim. Acta 44 (1977) 129-138.

[70] E. Sigfridsson, U. Ryde, Comparison of methods for deriving atomic charges from the electrostatic potential and moments, J. Comput. Chem. 19 (1998) 377-395.

[71] Y. Ohko, K.I. Iuchi, C. Niwa, T. Tatsuma, T. Nakashima, T. Iguchi, Y. Kubota, A Fujishima, 17 beta-estrodial degradation by $\mathrm{TiO}_{2}$ photocatalysis as means of reducing estrogenic activity, Environ. Sci. Technol. 36 (2002) 4175-4181.

[72] S.K. Rajak, D.C. Ghosh, Correlating the site selectivity of protonation in some ambidentate molecules in terms of the dual descriptor, Eur. Phys. J. D 66 (2012) 66.

[73] S. Yamada, Y. Naito, M. Takada, S. Nakai, M. Hosomi, Photodegradation of hexachlorobenzene and theoretical prediction of its degradation pathways using quantum chemical calculation, Chemosphere 70 (2008) 731-736. 